\title{
CONTROLE DO CARRAPATO Boophilus microplus (ACARI: IXODIDAE) EM SISTEMAS DE PRODUÇÃO DE LEITE DA MICRORREGIÃO FISIOGRÁFICA FLUMINENSE DO GRANDE RIO - RIO DE JANEIRO
}

\author{
CONTROL OF THE CATTLE TICK Boophilus microplus (ACARI: IXODIDAE) IN DAIRY \\ FARM SYSTEMS OF THE PHYSIOGRAPHIC MICRORREGION OF \\ GRANDE RIO, RIO DE JANEIRO, BRAZIL
}

\author{
Juracy de Castro Borba Santos Júnior ${ }^{1}$ John Furlong ${ }^{2}$ Erik Daemon $^{3}$
}

\section{RESUMO}

O objetivo do trabalho foi analisar os métodos de controle do carrapato Boophilus microplus realizados em três fazendas representativas dos sistemas de produção de leite da Microrregião Fisiográfica Fluminense do Grande Rio, Rio de Janeiro, levando-se em consideração o manejo das fazendas, o grau de sangue Bos taurus e Bos indicus dos rebanhos, os fatores climáticos e a prevalência estacional do carrapato. Para efeito de avaliação, foi utilizada a contagem periódica de fêmeas ingurgitadas medindo entre 4,5 e 8mm, no antímero direito de $20 \%$ das vacas em lactação de cada fazenda, durante um ano. A diferença no manejo das pastagens, a composição genética dos rebanhos e as condições climáticas influenciaram a prevalência estacional de B. microplus. A maior lotação animal por hectare, o elevado "stand" vegetativo das pastagens e o maior grau de sangue B. taurus contribuíram para as maiores infestações de carrapatos nas fazendas. $O$ controle de $\boldsymbol{B}$. microplus realizado pelos proprietários teve importância secundária em relação as outras atitudes de manejo dos rebanhos. Ficou evidenciado o uso excessivo e ineficiente de produtos químicos para o controle de B. microplus nas fazendas. Para implantação de medidas de controle estratégico do B. Microplus, fazem-se necessários esforços para a transferência e adoção dos resultados de pesquisas disponíveis aos produtores rurais.

Palavras-chave: bovinos, Boophilus microplus, manejo.

\section{SUMMARY}

The objective of the study was to analyse the control methods of the cattle tick, Boophilus microplus. The experiment was carried out on three farms of the dairy production systems of the Fluminense Physiographic Microregion of Grande Rio, Rio de Janeiro State, Brazil. Farm management, the Bos indicus and Bos taurus composition of herds, climatic factors and seasonal variation in tick infestation level of cattle was taken into account. Counts of engorged female ticks, measuring between 4.5 and $8.0 \mathrm{~mm}$, in $20 \%$ of the lactating cows of each farm, were carried out during one year, June 1996 to May, 1997. Pasture management differences, genetic composition of the herds and climatic conditions, influenced the seasonal incidence of $\boldsymbol{B}$. microplus. The highest cattle stocking rate per hectare, taller vegetative stand of pasture and greater proportion of $\boldsymbol{B}$. taurus genes in herds contributed to increase tick infestation on farms. The direct control of $\boldsymbol{B}$. microplus, carried out by the owners on farms, had a secondary importance compared to other factors of herd management. Excessive and inefficient use of chemical acaricide products was observed. Efforts should be made for the transfer and adoption of research results for rural producers to facilitate the implantation of strategic control measures against B. microplus.

Key words: bovine, Boophilus microplus, management.

\section{INTRODUÇÃO}

O Brasil é um país quase inteiramente tropical, com características climáticas que favorecem o desenvolvimento e a sobrevivência do $\boldsymbol{B}$. microplus na maioria dos meses do ano (EVANS, 1992). Com a introdução, nos rebanhos brasileiros, de animais com maior grau de sangue Bos taurus e o surgimento de novas variedades e espécies de gramíneas para pastejo (Brachiaria spp

\footnotetext{
${ }^{1}$ Médico Veterinário, Mestrando, Curso de Pós-graduação em Medicina Veterinária-Parasitologia Animal, UFRRJ.

${ }^{2}$ Médico Veterinário, Pesquisador, Embrapa Gado de Leite, Rua Eugênio do Nascimento 610, 36038-330, Juiz de Fora, MG. E-mail: john@cnpgl.embrapa.br. Autor para correspondência.

${ }_{3}^{3}$ Médico Veterinário, Professor Adjunto, Departamento de Parasitologia Animal, UFRRJ
} 
e Pennisetun spp), que permitem maior lotação por área, há o favorecimento da multiplicação, sobrevivência e desenvolvimento do carrapato (FURLONG, 1992). As forrageiras, comumente encontradas nos trópicos, possuem grande produtividade por hectare, folhas largas, com propagação rápida recobrindo todo o solo, estabelecendo um microhabitat favorável para o desenvolvimento da fase de vida livre do B. microplus (CORSI, 1990; BARROS \& EVANS, 1991; VERÍSSIMO, 1993). A variação da temperatura do ar é o fator climático que mais influencia a taxa e a duração da oviposição do B. microplus, sendo a temperatura do ar ideal entre $26,7^{\circ} \mathrm{C}$ a $29,4^{0} \mathrm{C}$ e o limite mínimo de $15^{\circ} \mathrm{C}$ e o máximo de $40,6^{\circ} \mathrm{C}$. Com o prolongamento do período de prépostura até a eclosão total das larvas, ocorre a diminuição desse instar na pastagem devido ao gasto energético, influenciando a variação estacional do $\boldsymbol{B}$. microplus (HITCHCOCK, 1955; BENNETT, 1974). De uma forma geral, o controle de B. Microplus, na Região Sudeste do Brasil, baseia-se em banhos carrapaticidas após a visualização de carrapatos adultos. Assim sendo, o número de banhos tende a ser muito elevado, variando com o método de aplicação, época do ano, raça do animal e custo do tratamento (MAGALHÃES \& LIMA, 1991). Existe uma distância entre as técnicas recomendadas pelos resultados de pesquisas disponíveis para o controle de $\boldsymbol{B}$. microplus e o que acontece no campo, como verificado por LEITE (1988), na Microrregião Fisiográfica Fluminense do Grande Rio, Rio de Janeiro. A pesquisa realizada por ROCHA (1996), no Estado de Minas Gerais, confirma esta hipótese ao revelar um incompleto conhecimento dos produtores sobre os prejuízos econômicos causados pelo carrapato. A implementação de um mecanismo de controle estratégico para o combate ao carrapato dos bovinos, levando em consideração as condições da localidade, promove benefícios ao produtor através da redução do custo e da facilidade de planejamento de um programa anual de gastos para o controle do carrapato (OLIVEIRA, 1993). A resistência do bovino ao B. microplus também deve ser levada em consideração para o controle do carrapato, visto que a resistência aumenta com maior grau de sangue Bos indicus no rebanho (SUTHERST et al. 1988; OLIVEIRA \& ALENCAR, 1990). Este trabalho objetivou avaliar os métodos de controle de $\boldsymbol{B}$. microplus, empregados em três fazendas representativas de sistemas de produção de leite da Microrregião Fisiográfica do Grande Rio RJ, levando-se em consideração o manejo nas propriedades, os graus de sangue $\boldsymbol{B}$. taurus e $\boldsymbol{B}$. indicus dos rebanhos, os fatores climáticos e verificando a prevalência estacional do carrapato.

\section{MATERIAL E MÉTODOS}

Foram selecionadas três fazendas com animais produtores de leite da Microrregião Fisiográfica Fluminense do Grande Rio, Rio de Janeiro, localizadas na latitude $22^{0} 45^{\prime} \mathrm{S}$ e longitude $43^{\circ} 41^{\text {' }}$ W, denominadas de Iguaçu, Esperança, Morrinho. Durante o período de junho de 1996 a maio de 1997, foram colhidos dados e realizadas contagens de fêmeas ingurgitadas de $\boldsymbol{B}$. microplus, de 14 em 14 dias, entre as oito e dez horas da manhã, utilizandose o antímero direito de $20 \%$ das vacas em lactação, sendo contadas as teleóginas com tamanho entre 4,5 e $8 \mathrm{~mm}$, segundo metodologia recomendada por WHARTON \& UTECH (1970). Utilizou-se um questionário, aplicado aos proprietários e funcionários, e observações pessoais para obtenção dos dados zootécnicos e de manejo nas fazendas estudadas. Os dados meteorológicos relacionados à temperatura $\left({ }^{0} \mathrm{C}\right)$, umidade relativa do ar $(\%)$ e precipitação pluviométrica $(\mathrm{mm})$ foram obtidos do posto de observação meteorológica da Estação Experimental de Itaguaí da Empresa de Pesquisa Agropecuária do Estado do Rio de Janeiro (PESAGRO-RIO).

A Fazenda Iguaçu apresentava uma produção de leite por vaca de cinco a oito litros. A composição do rebanho era de 28 vacas, 20 novilhas e 15 bezerras oriundas de cruzamento Holandês $x$ Gir, sendo $25 \%$ dos animais 31/32 H, $50 \% 15 / 16 \mathrm{H}$ e $7 / 8 \mathrm{H}$ e $25 \% 3 / 4 \mathrm{e} 1 / 2 \mathrm{H}$. As pastagens eram compostas de piquetes com Brachiaria decumbens para pastoreio e capim elefante (Pennisetum purpureum) para corte, sem adubação. A vedação de pastagem era de 21 dias na primavera-verão e 28 dias no outono-inverno e a lotação das pastagens de sete unidades animal por hectare. O horário da ordenha era das $6 \mathrm{~h}$ às $9 \mathrm{~h} 30 \mathrm{~min}$ e das $15 \mathrm{~h}$ às $17 \mathrm{~h} 30 \mathrm{~min}$, sendo oferecidos capim elefante picado e ração comercial com $20 \%$ de proteína para as vacas em lactação. A criação de bezerras era feita em bezerreiros coletivos e suspensos até 30 dias de vida e, a partir de 30 dias, em bezerreiros coletivos no chão, ficando durante o dia no pasto. $\mathrm{O}$ controle sanitário do rebanho era feito pelo proprietário, tendo assistência médica veterinária esporádica. Os tratamentos carrapaticidas eram em número de 15 ao ano, com intervalos de 15 a 30 dias, após visualização dos carrapatos pelo proprietário, através de pulverização com bomba costal, utilizando-se dois litros e meio de solução de Deltametrina $^{\mathrm{a}}$ e Triclorfon ${ }^{\mathrm{b}}$ nas diluições recomendadas pelos fabricantes, por bovino adulto e do uso de endectocidas injetáveis à base de Doramectin ${ }^{c}$, usado na metade da dose preconizada. Os produtos químicos eram escolhidos pelo proprietário mediante propaganda dos fabricantes e pelo resultado obtido 
após o uso. Os animais $1 / 2$ e $3 / 4$ Holandês x Gir não eram banhados com a mesma regularidade, pois apresentavam menores infestações do que os outros animais

A Fazenda Esperança apresentava uma produção de leite por vaca de dez a quinze litros. A composição do rebanho era de 86 vacas, 89 novilhas e 52 bezerras de cruzamento Holandês x Gir, sendo $50 \%$ dos animais $1 / 2 \mathrm{H}$ e $50 \% 3 / 4 \mathrm{H}$. As pastagens eram compostas de piquetes com $\boldsymbol{B}$. decumbens para pastoreio e capim elefante, $\boldsymbol{P}$. purpureum, adubados cinco vezes por ano. A vedação de pastagem era de 40 dias na primavera-verão e 70 dias no outono inverno, sendo utilizada a lotação de uma unidade animal por hectare. A ordenha era realizada das 3 às 6 horas e das 13 às 15 horas, ocorrendo suplementações alimentares no cocho, com o capim elefante picado, ração comercial com $20 \%$ de proteína e cevada. A criação de bezerras era feita em bezerreiros individuais e suspensos até 30 dias de vida, e em bezerreiros suspensos e coletivos de 30 dias até os três meses de idade. A partir de três meses, passavam para alojamentos coletivos no chão, freqüentando piquetes de pastagens para essa categoria, durante o dia. Durante todo o experimento ocorreram surtos periódicos de babesiose nas bezerras a partir de três meses de idade. O controle sanitário era feito pelo proprietário sobre orientação do médico veterinário. Os tratamentos carrapaticidas eram feitos através de pulverizações, com bomba costal, utilizando-se cinco a sete litros de solução de Ami$\operatorname{traz}^{\mathrm{d}}$ por animal adulto e Doramectin ${ }^{\mathrm{c}}$ injetável, conforme visualização do carrapato pelo proprietário, em intervalos variando de dez a 30 dias, dentro das recomendações técnicas dos fabricantes, totalizando 15 tratamentos no ano. Os produtos químicos eram escolhidos pelo proprietário mediante propaganda dos fabricantes e pelo resultado obtido após o uso.

A Fazenda Morrinho apresentava uma produção de leite por vaca de vinte a vinte e cinco litros. A composição do rebanho era de 150 vacas, 58 novilhas e 160 bezerras de cruzamento Holandês x Gir, sendo $25 \%$ dos animais 31/32 H, 50\% 15/16 e $7 / 8 \mathrm{H}$ e $25 \% 3 / 4$ e $1 / 2 \mathrm{H}$. As pastagens eram compostas de piquetes mistos de $\boldsymbol{B}$. mutica e $\boldsymbol{P}$. purpureum, para pastoreio, adubadas cinco vezes no ano com adubo químico. A vedação de pastagem era de 21 dias na primavera-verão e 40 dias no outonoinverno, sendo utilizada a lotação de 5 unidades animal por hectare. $\mathrm{O}$ horário da ordenha na primavera e no verão ocorria das 5 até às 8 horas e das 16 horas às 18 horas. No outono e no inverno, a ordenha era realizada das 4 às 7 horas e das 15 às 17 horas. Eram feitas suplementações alimentares com ração balanceada e produtos da agroindústria (cevada, bagaço de laranja peletizada e caroço de algodão). A criação de bezerras era feita em baias individuais e suspensas até 30 dias de vida, e em baias coletivas e suspensas até os 90 dias de vida. Após 90 dias, passavam a ficar alojadas em piquetes para bezerras. O controle sanitário era feito por médico veterinário mensalmente. Os tratamentos carrapaticidas eram realizados conforme a constatação da presença dos carrapatos, através do uso de pulverização com Amitraz ${ }^{\mathrm{d}}$ e Flumethrin ${ }^{\mathrm{e}}$ dentro das recomendações técnicas dos fabricantes, com relação à diluição e quantidade, com intervalos de 10 a 30 dias durante todo o ano, num total de 21 tratamentos, escolhidos pela divulgação dos fabricantes e pelo resultado obtido com o uso. Os animais $1 / 2$ e 3/4 Holandês x Gir não eram banhados com a mesma regularidade, pois apresentavam menores infestações do que os outros animais.

Para análise estatística, os dados foram transformados em logaritmo, como sugerido por WHARTON \& UTECH (1970), sendo aplicada a análise de variância e o teste de Tukey para comparar as médias (GOMES, 1978). As análises de variância foram feitas levando-se em consideração as propriedades e os meses; propriedades e estação do ano, sendo inverno (junho, julho e agosto), primavera (setembro, outubro e novembro), verão (dezembro, janeiro e fevereiro) e outono (março, abril e maio).

\section{RESULTADOS}

Através da análise de variância, pôde-se verificar que houve diferença significativa $(\mathrm{P}<0,05)$ entre o número de carrapatos nas contagens realizadas nas Fazendas Iguaçu e Morrinho com o número nas contagens efetuadas na Fazenda Esperança. $\mathrm{Na}$ tabela 1, observam-se as diferenças $(\mathrm{P}<0,05)$ nas médias mensais das contagens de carrapatos, sendo que o mês de junho apresentou a maior média e o de janeiro a menor. A estação do ano afetou significativamente $(\mathrm{P}<0,05)$ o número de carrapatos. As médias obtidas nas contagens de carrapatos de acordo com a estação do ano encontram-se na tabela 2. Não houve interação $(\mathrm{P}>0,05)$ entre fazendas e meses e entre fazendas e estação do ano. A maior média foi obtida nas contagens de carrapatos durante o inverno, e apresentou diferença significativa com a obtida no verão. Houve uma tendência de diminuição da média nas contagens de carrapatos, do inverno para o verão e o aumento, do verão para o inverno. Não ocorreu diferença significativa entre as médias nas contagens de carrapatos entre as estações do inverno e verão com a da primavera e outono. 
Tabela 1 - Médias mensais nas contagens de B. microplus, respectivos errospadrões e números de tratamentos carrapaticidas, referentes ao período de junho de 1996 a maio de 1997, nas fazendas estudadas, na microrregião fisiográfica Fluminense do Grande Rio, Rio de Janeiro.

\begin{tabular}{|c|c|c|c|c|c|c|c|}
\hline \multirow[t]{3}{*}{ Meses/Ano } & \multicolumn{7}{|c|}{ Fazendas } \\
\hline & \multicolumn{2}{|c|}{ Iguaçu } & \multicolumn{2}{|c|}{ Esperança } & \multicolumn{2}{|c|}{ Morrinho } & \multirow[t]{2}{*}{ Médias } \\
\hline & Médias & Trat. & Médias & Trat. & Médias & Trat. & \\
\hline Junho/96 & 57,73 & 02 & 9,03 & 01 & 34,68 & 02 & $33,81 \pm 0,06^{\mathrm{a}}$ \\
\hline Julho/96 & 15,65 & 01 & 2,67 & 01 & 13,18 & 01 & $10,50 \pm 0,06^{\mathrm{abc}}$ \\
\hline Agosto/96 & 7,56 & 01 & 4,25 & 01 & 9,62 & 01 & $7,14 \pm 0,05^{\mathrm{bcd}}$ \\
\hline Setembro/96 & 12,70 & 01 & 3,01 & 02 & 24,68 & 02 & $13,46 \pm 0,06^{\mathrm{abc}}$ \\
\hline Outubro/96 & 17,33 & 01 & 3,26 & 01 & 22,04 & 02 & $14,21 \pm 0,06^{\mathrm{abc}}$ \\
\hline Novembro/96 & 15,54 & 01 & 4,65 & 01 & 11,20 & 01 & $10,47 \pm 0,06^{\mathrm{abc}}$ \\
\hline Dezembro/96 & 9,93 & 01 & 6,33 & 01 & 12,98 & 02 & $9,75 \pm 0,06^{\mathrm{abc}}$ \\
\hline Janeiro/97 & 3,60 & 01 & 1,30 & 01 & 2,23 & 02 & $2,38 \pm 0,05^{\mathrm{d}}$ \\
\hline Fevereiro/97 & 5,97 & 01 & 2,74 & 01 & 3,45 & 02 & $4,05 \pm 0,06^{\mathrm{cd}}$ \\
\hline Março/97 & 9,83 & 02 & 2,16 & 02 & 5,27 & 03 & $5,75 \pm 0,06^{\text {bcd }}$ \\
\hline Abril/97 & 3,46 & 01 & 1,76 & 02 & 5,16 & 01 & $3,46 \pm 0,06^{\mathrm{cd}}$ \\
\hline Maio/97 & 21,59 & 02 & 9,68 & 01 & 14,32 & 02 & $15,20 \pm 0,06^{\mathrm{ab}}$ \\
\hline Médias & $15,07 \pm$ & $03^{\mathrm{a}}$ & $4,24 \pm$ & $0,03^{\mathrm{b}}$ & $13,23 \pm$ & $0,03^{\mathrm{a}}$ & $10,85 \pm 0,02$ \\
\hline
\end{tabular}

Médias seguidas pela mesma letra não diferem entre si, em nível de $5 \%$ de probabilidade, pelo Teste de Tukey.

\section{DISCUSSÃO}

A variação de graus de sangue $\boldsymbol{B}$. taurus e B. indicus dos rebanhos das fazendas analisadas parece ter contribuído para a diferença estatística das médias nas contagens de carrapatos entre as fazendas, pois as menores médias ocorreram na Fazenda Esperança, que possuía rebanho com menor grau de sangue $\boldsymbol{B}$. taurus e maior de $\boldsymbol{B}$. indicus, em comparação com as Fazendas Iguaçu e Morrinho, podendo ser evidenciada esta influência, já que os animais mestiços $1 / 2$ e 3/4 Holandês x Gir das Fazendas Iguaçu e Morrinho eram banhados com menor regularidade em comparação aos outros animais. Esta observação está em concordância com os trabalhos realizados por SUTHERST et al. (1988), na Austrália, e por MORAES et al. (1989) e OLIVEIRA \& ALENCAR (1990), no Brasil.

A baixa lotação animal por hectare observada na Fazenda Esperança (1ua/ha) pode ter contribuído para a menor exposição de hospedeiros ao carrapato, ao contrário das Fazendas Morrinho e Iguaçu que, possuindo maior lotação de unidades animal por hectare, $5 \mathrm{ua} / \mathrm{ha}$ e $7 \mathrm{ua} / \mathrm{ha}$ respectivamente, possibilitaram maior exposição aos carrapatos, colaborando em parte para as diferenças nas médias do número de carrapatos encontradas entre essas fazendas, estando de acordo com os estudos de FURLONG (1992) e VERÍSSIMO (1993).

Com a semelhança genética dos animais das Fazendas Iguaçu e Morrinho, era de se esperar produção de leite semelhante, entretanto, constata-se maior produção de leite por vaca na Fazenda Morrinho e médias de contagens de carrapatos sem diferença estatística significativa, o que demonstra o efeito relacionado ao manejo usado nessas fazendas. A diferença de manejo demonstrou ser um fator que influenciou a produtividade e as infestações de carrapatos, podendo ser verificado quando se compara as Fazendas Iguaçu e Esperança, verificando-se menor média de contagens de carrapatos e maior produção de leite por vaca na Fazenda Esperança, que era constituída de um rebanho com maior grau de sangue $\boldsymbol{B}$. indicus do que B. taurus.

As forrageiras utilizadas nas fazendas estudadas são comumente encontradas nos trópicos, possuindo grande produtividade por hectare, propagando-se rapidamente, recobrindo todo o solo e apresentando folhas largas, estabelecendo um microclima adequado para o desenvolvimento da fase de vida livre do $\boldsymbol{B}$. microplus, como verificado por VERÍSSIMO (1993), podendo ter contribuído para a ocorrência do carrapato durante todo o período do experimento. A rotação de pastagens empregada nas Fazendas Iguaçu e Morrinho, determinou períodos de descanso de 21 dias na primavera-verão e 28 a 40 dias no outono-inverno, respectivamente, os quais são insuficientes para promover diminuição na população de carrapatos por ausência de alimento para as larvas infestantes, o que ocorre com, no mínimo, 60 dias de vedação de pastagens, como verificado na Região Sudeste do Brasil por FURLONG (1998).

A vedação de pastagens da Fazenda Esperança se aproxima do preconizado por VERÍSSIMO \& MACHADO (1995), que recomendam uma vedação de 30 dias no verão e 120 no outono-inverno, para auxiliar no controle do carrapato. Contudo, tal sistema não segue as recomendações técnicas de produção animal, onde o descanso não deve ser superior a 30 dias na primavera-verão e 45 dias no outono-inverno, ficando evidente a sobra de pastagens, com perdas econômicas, uma vez que as pastagens representam 40 a $60 \%$ do custo da produção leiteira, como relatado por MATOS (1997). Dessa forma, parece que o controle do carrapato dos bovi- 
Tabela 2 - Médias nas contagens de B. microplus, de acordo com a estação do ano, e respectivos erros-padrões no período de junho de 1996 a maio de 1997, nas três fazendas estudadas, na microrregião fisiográfica Fluminense do Grande Rio, Rio de Janeiro.

\begin{tabular}{|c|c|c|c|c|}
\hline \multirow[t]{2}{*}{ Estação do ano } & \multicolumn{3}{|c|}{ Fazendas } & \multirow[t]{2}{*}{ Médias } \\
\hline & Iguaçu & Esperança & Morrinho & \\
\hline Inverno (Jun-Jul-Ago) & 26,98 & 5,32 & 19,16 & $17,15 \pm 0,07^{\mathrm{a}}$ \\
\hline Primavera (Set-Out-Nov) & 15,19 & 3,64 & 19,31 & $12,71 \pm 0,07^{\mathrm{ab}}$ \\
\hline Verão (Dez-Jan-Fev) & 6,50 & 3,46 & 6,22 & $5,39 \pm 0,07^{\mathrm{b}}$ \\
\hline Outono (Mar-Abr-Mai) & 11,62 & 4,53 & 8,23 & $10,87 \pm 0,07^{\mathrm{ab}}$ \\
\hline Médias & $15,07 \pm 0,06^{\mathrm{a}}$ & $4,24 \pm 0,06^{\mathrm{b}}$ & $13,23 \pm 0,06^{\mathrm{a}}$ & \\
\hline
\end{tabular}

Médias seguidas pela mesma letra não diferem entre si, em nível de $5 \%$ de probabilidade, pelo Teste de Tukey.

nos em propriedades leiteiras com elevada produção de pastagens deverá ser feito primordialmente através de banhos ou tratamentos acaricidas estratégicos, evitando-se assim a possibilidade de redução na produção de leite e o aumento do custo de produção, decorrente do baixo efeito higienizador da pastagem vedada por períodos menores do que 60 dias.

Na Fazenda Esperança, a exposição das bezerras a partir dos 3 meses de idade aos carrapatos transmissores de Babesia spp, em piquetes contaminados por outros animais, contribuiu para os surtos de Babesiose, fato já verificado por BOURNE $\boldsymbol{e t} \boldsymbol{a l}$. (1988). Nas fazendas estudadas, os métodos de controle empregados e, basicamente, relacionados a tratamentos acaricidas após visualização de número elevado de carrapatos, não estão de acordo com as recomendações técnicas disponíveis e com as normas do MINISTÉRIO DA AGRICULTURA (1987), considerando-se o uso excessivo de tratamentos durante o ano, o volume de solução carrapaticida utilizado por animal e a utilização de endectocida para vacas em lactação.

Verificando-se a ocorrência das maiores infestações do B. microplus nas três fazendas, no mês de junho e na estação de inverno (junho a agosto), observou-se que a variação da temperatura do ar, aparentemente, esteve dentro de um padrão adequado para o desenvolvimento do B. microplus, visto que a menor média de temperatura apresentouse entre $23,2{ }^{\circ} \mathrm{C}$ e $23,8^{0} \mathrm{C}$ (Figura 1), estando dentro dos limites de temperatura para que não haja inibição da oviposição da fêmea ingurgitada de $\boldsymbol{B}$. microplus, como verificado por HITCHCOCK (1955) e BENNETT (1974).
As variações climáticas (principalmente temperatura do ar elevada) ocorridas no verão, meses em que foi constatado o menor número de carrapatos, parecem ter sido satisfatórias para induzir a mortalidade de larvas nas pastagens, por estresse calórico, nas três fazendas, como sugerido por SOUZA (1990), no Brasil e UTECH et al. (1983), na Austrália.

Os métodos e meios utilizados pelos fazendeiros e médicos veterinários para o controle do carrapato foram empíricos. Tal observação demonstra uma certa distância existente entre as técnicas recomendadas pelos resultados de pesquisas disponíveis e o que ocorre no campo, já tendo sido relatado por LEITE (1988), em trabalho realizado na mesma microrregião fisiográfica. O manejo utilizado pelos fazendeiros, priorizado apenas para a produção, mostra que as parasitoses são consideradas apenas curativamente, e que, possivelmente, os proprietários não são favoráveis a modificações de manejo que por ventura possam, ainda que hipoteticamente, comprometer a produção leiteira a curto prazo.

$\mathrm{Na}$ eventual hipótese de se implantar um controle estratégico do B. microplus na microrregião estudada, e possivelmente em outras, haverá necessidade de realizar-se, numa primeira etapa, um levantamento completo das atividades desenvolvidas nas fazendas, identificando-se e analisando-se as características culturais da população alvo, para que se obtenham informações suficientes que possam contribuir para o esclarecimento dos fazendeiros, convencendo-os da importância do trabalho a ser realizado. A importância desse levantamento já havia sido destacada por ROCHA (1996), cuja pesquisa revelou o conhecimento incompleto por parte dos proprietários dos prejuízos econômicos causados pelo carrapato.

Analisados os dados obtidos, pode-se recomendar para esses produtores que busquem orientação técnica junto aos centros de pesquisas agropecuários da região, para que haja transferência do conhecimento disponível, principalmente no que se refere à diluição correta dos produtos, tratamentos adequados, aplicação estratégica baseada na biologia do carrapato na região, conscientização do problema da resistência do carrapato aos carrapaticidas baseado no mau uso e aplicação indevida de produtos com resíduo na carne e no leite. 


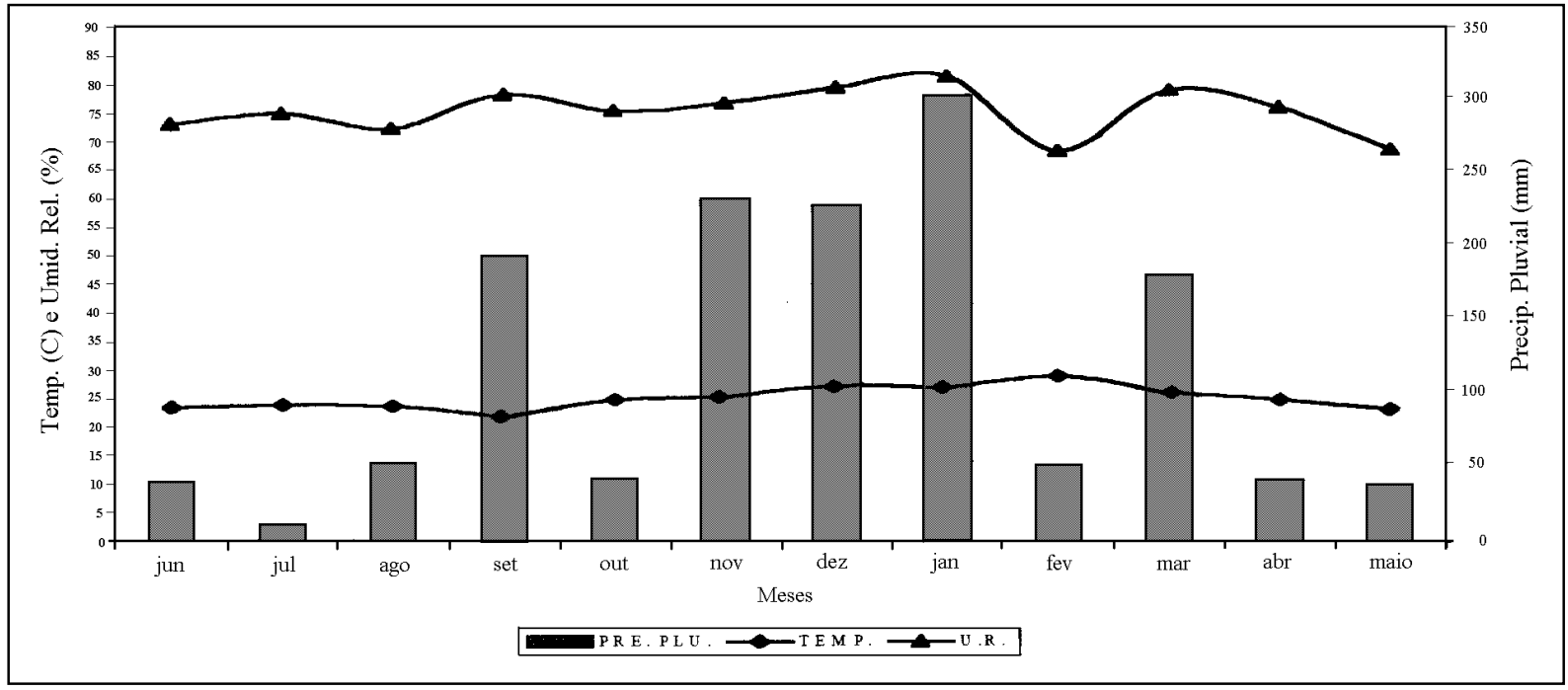

Figura 1 - Médias da temperatura média $\left({ }^{\circ} \mathrm{C}\right)$, da umidade relativa $(\%)$ e da precipitação pluviométrica $(\mathrm{mm})$ da Microrregião Fisiográfica Fluminense do Grande Rio, Rio de Janeiro, no período de junho de 1996 a maio de 1997.

\section{CONCLUSÕES}

As variáveis climáticas influenciaram na prevalência estacional do $\boldsymbol{B}$. microplus. A maior lotação animal por hectare, o elevado stand vegetativo das pastagens e o maior grau de sangue $\boldsymbol{B}$. taurus contribuíram para as maiores infestações de carrapatos nas fazendas. Não havia uma maior preocupação dos proprietários com a eficiência dos tratamentos acaricidas, acarretando assim fracasso no controle e um aumento de gasto, representado pelo elevado número de tratamentos utilizados nas propriedades. O uso excessivo de produtos químicos, para o controle do B. microplus verificado durante a realização do experimento, predispôs a riscos de contaminação do meio ambiente, do homem e desenvolvimento de cepas de carrapatos resistentes. Há necessidade de campanhas de convencimento junto aos proprietários para que sejam implantadas medidas de controle estratégico do B. microplus.

\section{FONTES DE AQUISIÇÃO}

${ }^{\text {a }}$ Butox, Quimio.

${ }^{\mathrm{b}}$ Neguvon, Bayer.

${ }^{\mathrm{c}}$ Dectomax, Pfizer.

d Triatox, Coopers.

e Bayticol, Bayer.

\section{REFERÊNCIAS BIBLIOGRÁFICAS}

BARROS, A.T.M., EVANS, D.E. Forrageiras com potencial anticarrapato. Ação de substâncias voláteis em larvas infestantes de Boophilus microplus (CAN.,1887). Pesq Agropec Bras, v.26, n.4, p.499-503, 1991.
BENNETT, G.F. Oviposition of Boophilus microplus (Canestrini) (Acarida: Ixodidae). II Influence of temperature, humidity and light. Acarologia, v.16, n.2, p.250-257, 1974.

BOURNE, A.S., SUTHERST, R.W., SUTHERLAND, I.D., et al . Ecology of the cattle tick (Boophilus microplus) in subtropica; Australia. III. Modelling populations on different breeds of cattle. Aust J Agri Res, v.39, p.309-318, 1988.

CORSI, M. Novas tecnologias de produção animal. Campinas : SBZ, 1990. Produção e qualidade de forrageiras tropicais: p.171-193

EVANS, D.E. Tick infestation of livestock and tick control methods in Brazil: a situation report. Insect Sci Applic, v.13, n 4, p.629-643, 1992.

FURLONG, J. Controle do carrapato dos bovinos na Região Sudeste do Brasil. In: CHARLES, T.P., FURLONG, J. Doenças parasitárias dos bovinos de leite. Coronel Pacheco : EMBRAPA-CNPGL, 1992. p.29-54.

FURLONG, J. Poder infestante de larvas de Boophilus microplus (Acari:Ixodidae) na Zona da Mata do Estado de Minas Gerais. Ciência Rural, v.28, n.4, p.635-640, 1998.

GOMES, F. P. Curso de estatística experimental. Piracicaba : Nobel, 1978. 430p.

HITCHCOCK, L.F. Studies of the non-parasitic stages of the cattle tick, Boophilus microplus (Canestrini) (Acarina: Ixodidae). Aust J Zool, v.3, p.293-311, 1955.

LEITE, R.C. Boophilus microplus (Canestrini, 1887). Susceptibilidade, uso atual e retrospectivo de carrapaticida em propriedades das Regiões Fisiogeográficas da Baixada do Grande-Rio e Rio de Janeiro, uma abordagem epidemiológica. Itaguaí, 1988. 151p. Tese (Doutorado em Medicina Veterinária) - Curso de Pós-graduação em Medicina Veterinária, Universidade Federal Rural do Rio de Janeiro, 1988.

MAGALHÃES, F.E.P., LIMA, J.D. Controle estratégico do Boophilus microplus (Canestrini, 1887) (Acarina: Ixodidae) 
em bovinos da região de Pedro Leopoldo, Minas Gerais, Brasil. Arq Bras Med Vet Zoot, v.43, n.5, p.423-431, 1991.

MATOS, L.L. Produção de leite a pasto. In: REUNIÃO ANUAL DA SOCIEDADE BRASILEIRA DE ZOOTECNIA, 1997, Juiz de Fora, MG. Anais... Juiz de Fora : SBZ, 1997. 230p. p.169-193.

MINISTÉRIO DA AGRICULTURA. Normas para registro de parasiticidas de uso pecuário no Brasil. Brasília : Ministério da Agricultura, 1987. 19p.

MORAES, F.R., ROCHA, U.F., COSTA, A.J., et al. Ecologia de carrapatos XXV - Correlação entre a resistência natural de hospedeiros taurinos e zebuínos e a biologia de Boophilus microplus (CANESTRINI). Ars Veterinaria, v.5, n.1, p.6778,1989 .

OLIVEIRA, P.R. Controle estratégico do Boophilus microplus (CANESTRINI, 1887) em bovinos de propriedades rurais dos municípios de Lavras e Entre Rios de Minas, Minas Gerais. Belo Horizonte, 1998. 97p. Tese (Mestrado em Medicina Veterinária) - Curso de Pós-graduação em Ciência Animal, Universidade Federal de Minas Gerais, 1993.

OLIVEIRA, G.P., ALENCAR, M.M. Resistência de bovinos de seis graus de sangue holandês-guzerá ao carrapato (Boophilus microplus) e ao berne (Dermatobia hominis). Arq Bras Med Vet Zoot, v.42, n.2, p.127-135, 1990.

ROCHA, C.M.B.M. Caracterização da percepção dos produtores do Município de Divinópolis, MG sobre a importância do carrapato Boophilus microplus e fatores determi- nantes das formas de combate utilizadas. Belo Horizonte, 1996. 205p. Tese (Mestrado em Medicina Veterinária) - Curso de Pós-graduação em Ciência Animal, Universidade Federal de Minas Gerais, 1996.

SOUZA, A.P. Variação populacional dos principais ixodídeos parasitas de bovinos e eqüinos em diferentes condições de manejo, nos municípios de Paracambi e Itaguaí no Estado do Rio de Janeiro. Itaguaí, 1990. 81p. Tese (Doutorado em Medicina Veterinária) - Curso de Pós-graduação em Medicina Veterinária, Universidade Federal Rural do Rio de Janeiro, 1990.

SUTHERST, R.W., MAYWALD, G.F., BOURNE, A.S., et al. Ecology of the cattle tick (Boophilus microplus) in subtropica; Australia. II. Resistence of different breeds of cattle. Aust J Agri Res, v.39, p.299-308, 1988.

UTECH, K. B.W., SUTHERST, R.W., DALLWITZ, M.J., et al. A model of the survival of larvae of the cattle tick, Boophilus microplus on pasture. Aust J Agri Res, v.34, p.63-72, 1983.

VERÍSSIMO, C.J. Controle do carrapato dos bovinos. Jaboticabal : FUNEP, 1993. 26p.

VERÍSSIMO, C.J., MACHADO, S.G. Fase de vida livre do ciclo evolutivo do carrapato Boophilus microplus. Zootecnia., v.33, n.2, p.41-53, 1995 .

WHARTON, R.H., UTECH, K.B.W. The relation between engorgement and dropping of Boophilus microplus (Canestrini) (Ixodidae) to the assessment of tick numbers on cattle. J Aust Entomol Soc, v.9, p.171- 182, 1970.

Ciência Rural, v. 30, n. 2, 2000. 